\title{
STUDENT PERCEPTION OF FORMATIVE PEER REVIEW
}

\author{
Alex Krouglov \\ University College London, UK \\ Rezekne Academy of Technologies, Latvia
}

\begin{abstract}
The present paper covers our initial research findings of postgraduate student perceptions of formative in-class peer review in relation to their presentations, research, professional communication, and language skills. The paper also aims to assess the impact it may have on learning at advanced level of language training, and explores how peer review approach used in classes changes student perception of its benefits and challenges and contributes to the development of presentation, language and research skills. Besides the development of speaking skills, critical thinking and argumentation, peer review enables them to assess themselves better, to think more about the target audience and encourages better course and research engagement and collaborative learning. In our research, the students were asked to provide in-class peer review of presentations made by students on various aspects of their research as part of the connected curriculum framework established at the University College London.
\end{abstract}

Keywords: formative in-class peer review; connected curriculum framework; constructive feedback.

\section{Introduction}

Peer review has been a very important development in establishing new innovative and more effective modes of formative feedback to students. Regular student assessments of teaching and learning in the Higher Education in the UK show that students particularly value regular feedback on their progress and performance. They always ask for more feedback during their university studies. At the same time, we have witnessed a stronger movement in educational theory from teacher-focused to learner-centred approaches. More and more studies support active learning courses where students become engaging participants in the learning process (Springer et al., 1999). It is for this and many other reasons, peer review has been researched by many academics working in various subjects, especially in the field of English language training. Researchers addressed, for example, an array of issues linked to positive impact of peer review on enhancing students' writing skills (Bainbridge \& Sandford-Couch, 2018; Huisman et al., 2019; Liu \& Carless, 2006; Malyuga, 2009; Min, 2006; Mulder et al., 2014; Nicol, 2014). However, "student perceptions of formative peer review remain relatively 
understudied” (Mulder et al., 2014, 159), especially in the field of formative inclass oral peer review of presentations made by students or any other oral activities, e.g. participation in role-plays or discussions.

Some researchers suggest that peer and self-assessment can cut down the work for lecturers while actively engaging students in assessing the work and developing a better understanding of assessment criteria and requirements in a discipline (Higgins et al., 2010). There are many other studies, which deal with the areas where peer review can be used effectively as part of the formative assessment. Our research aims to answer the question about student perception of peer review of in-class activities, which have been developed in order to enhance presentation and research skills of students. This study addresses the issue of how valuable peer feedback of other students may be for their own development during the course.

The definition of formative peer review is based on the definition of peer assessment by Topping (1998) and the definition of formative peer feedback for writing performance provided by Huisman et al. (2019). In-class formative peer review is defined in our research as an arrangement whereby students communicate information to peers of similar status, which may contribute to the improvement of presentation, language or any other relevant skills of the student delivering a presentation. By other relevant skills, we mean research skills, the use and application of methodologies in the research, knowledge relevant to a particular domain or subject, and other issues covered in student presentations.

In this research, we had two cohort of postgraduate students in our Advanced and Intermediate Russian language modules. In each module, the students were asked to make several presentations on the progress of their research in a specific domain during the academic year. The presentations usually start from four to five minutes in the autumn semester to eight or ten minutes towards the end of the module. The content of the presentation is usually based on their research in one of the domains depending on their major subject covering issues, for example, in the fields of foreign and domestic policy of a chosen country or region, economic and financial issues, literature, arts and many other subjects. On the whole, the content of the presentation is left to the students, however, they are supposed to explain why they chose the topic, what their main and secondary research questions, what methodology they selected and explain why the chosen approaches are the most effective in analysing the topic and provide answers to research questions. Students may also outline their research process and analyse any challenges that they have encountered.

After the presentation, the students are given time to ask questions and provide constructive formative peer feedback to presenters during the class. It usually achieves several goals, for example, it enables them to improve their presentation skills and gain necessary confidence in presenting various issues to 
their peers. The presentation also provides them with a unique opportunity to explore other routes in the research process, enhance their language skills, as well as develop further other skills, e.g. analytical and critical thinking, originality of research, focus on the main research questions. In this process, students who give and receive feedback benefit from this activity since it allows them to assess presentations, research and language skills of their fellow students and, at the same time, to think about their own presentations, similar or different items in their research and considerably enrich their language repertoires. Students were not asked to generate a mark since this was a formative in-class assessment aimed at improving skills and initiating the discussion around various research fields. At the outset, some students thought that giving a feedback by saying that the presentation was 'good' could be sufficient. The teacher's role was to explain and train students as to what feedback they should provide to make it useful for further development of all students engaged in this process. There has been a general misconception that positive feedback is not valuable, which is another issue we wanted to explore and test in our research.

\section{Methodology}

An anonymous short questionnaire was developed for postgraduate students, which included open questions asking participants to comment on various aspects of peer review. Students were asked whether they view it as a useful or not very useful exercise and explain their reasons. They were also asked to think about challenges either in giving and receiving peer feedback as well as provide any other comments or observations. Before the survey began, the questionnaire was tested on a small group of students in order to receive any feedback and suggestions for enhancing the questions or explanations.

When compiling a questionnaire, the following background parameters were taken into consideration:

- $\quad$ students already completed undergraduate studies in the UK or overseas and may have had some exposure to peer review in other institutions;

- $\quad$ students are usually very interested in developing their research skills in their chosen subjects;

- the university encourages connected curriculum framework for research-based education which supports student research and makes strong connections across disciplines;

- researcher's previous positive experience of using formative peer feedback in teaching interpreting;

- moving from teacher-centred education to a community of practice where all participants are contributing to the development of their own skills; 
- encouraging engagement of students and developing initiative, analytical and critical thinking, originality and the ability to liaise effectively with the audience.

Students were asked to complete the same questionnaire at the beginning and the end of Advanced and Intermediate Russian Language modules. The majority of students were engaged in research in politics, international politics and policy and security, i.e. $83 \%$ of the cohort. In addition, there were two students engaged in literature and arts research, and one - in economics. Although the participation in filling out the questionnaire was voluntary, all enrolled students completed their questionnaires and provided feedback on various aspects of peer review. The total number of students who participated in the research was 26 in 2018/19, at the same time, only 15 students participated in filling in questionnaires at the beginning of the module in 2019/20. The data from the latter academic year was not included in the present research. We therefore consider this research as work in progress. It is therefore, the current paper covers some preliminary findings based on questionnaires completed by students during the academic year 2018/19, i.e. at the beginning and the end of their postgraduate modules.

We received feedback from 26 postgraduate students at the beginning and at the end of their modules. The majority of students had studied previously in the UK and overseas and were exposed to a range of approaches in Higher Education. However, it was established that around one third of students had no previous experience of studying in the UK. Almost $80 \%$ of students were in the same age group of $20-30$ years old. There were also $12 \%$ of $30-40$ years old students and $8 \%$ of students in the $40-50$ years age group. The groups were balanced along the line of $41 \%$ male and $59 \%$ female participants in our study. Overall, the data mentioned above reflects demographic composition of students in these and other modules across the university.

The discussion is divided into two parts where we will analyse the results of our survey at the beginning and at the end of the course. Students provided numerous comments for the qualitative analysis of peer review.

\section{Student perception of peer review at the beginning of the modules}

When analysing the comments, it was established that only $14 \%$ of postgraduate students were not familiar with the term and concept of a "peer review" and therefore were not able to comment at the beginning of their modules. All other students confirmed that they previously received and gave feedback; however, only $28 \%$ of participants confirmed that they had been engaged in the provision of peer review orally in class before, while other students participated in the provision of written peer feedback or orally in one-to-one situations. These 
results indicated a possible challenge for the lecturer when introducing formative peer review as part of in-class assessment of research presentations.

Comments in the initial questionnaire also confirmed that giving and receiving peer feedback may encounter numerous challenges. Students particularly mentioned different perceptions of research work and presentations based on previous experiences in their home or study countries. Culture specific issues were identified as key in engaging students representing various cultures and experiences since they completed their undergraduate degrees at educational institutions around the world. The issue was whether students would be able to understand the full significance of in-class formative peer review and learn how to provide relevant and inoffensive feedback or suggestions to their peers. The role of the lecturer here is becoming crucial in creating a friendly and collaborative atmosphere where all students feel as part of the team or community of practice aiming to achieve a common goal. In view of the last statement, a couple of students pointed to the fact that it was important to understand and predict how another student may react to peer feedback from other fellow students.

There were several students who were previously engaged in oral in-class peer review in other institutions and thought that it was not always useful as sometimes students who provided feedback "did not know the subject well" but "just wanted to show off". Overall, they thought that this experience might be discouraging to some students or could even have a negative impact on friendly relations, especially when "criticising someone". As we can see from the feedback received at the beginning of the modules, some students felt strongly about the challenges peer-review might pose and doubted the usefulness of the exercise for developing necessary skills and their research.

Nevertheless, a significant proportion of students (around 34\%) felt that peer feedback was useful because it could provide practical and suitable suggestions for improvement, as well as indicate whether the presentation and messages were clear and transparent for others. A few other students, while agreeing that peer feedback could be a useful tool for the development of research and relevant skills, they also stated that it would depend on the guidance and clearness of instructions provided by lecturers. Some comments specifically addressed the usefulness of peer review and what feedback they would benefit from, e.g. "students will benefit from concrete and constructive feedback". Respondents also shared instances of their positive experience in other institutions and courses they had before. They particularly pointed out that this could work extremely well in very small tutorials, e.g. in groups of two students where students could receive feedback from their tutor and another student.

A small group of students reported that they valued the feedback of fellow students, e.g. "I take feedback from my peers really seriously". However, a couple 
of other students thought that anonymous feedback allowed more open and frank feedback, while in-class feedback might restrict the students in expressing themselves and their feedback would be limited, since they would "need to be polite" and avoid any comments which might be viewed as offensive by some students. There were two students who misunderstood the question about the usefulness of peer feedback and thought that the question was about the feedback to teachers.

The above feedback from students analysed here allowed us to conclude that at the beginning of the modules, students were concerned about the usefulness of in-class formative peer review and the ability of other fellow students to provide clear, constructive, and inoffensive feedback, which would allow them to improve their skills and develop their research further. At the same time, they showed some uncertainty and doubted whether they would receive clear guidelines and how it would be organised effectively during their classes.

\section{Student perception of peer review at the end of the modules}

During the entire modules over two semesters, students were asked to present their research with slides and without slides. While presentations were generally four to five minutes in the autumn semester, the time for presentations increased to eight or ten minutes in the spring semester. Lecturer provided guidance as to how the sessions will be organised, and what feedback will be provided by students to their peers. Students also received some vocabulary lists and phrases, which could be used in the provision of feedback. All presentations were followed by questions from students and the lecturer, after which students were given time to provide oral in-class formative feedback to presenters on various aspects of their performance, e.g. presentation and language skills, the actual topic, research methodology, research questions, literature review and other relevant issues. While receiving peer feedback all presenters were asked to respond to feedback and agree or disagree with the comments made by other students and provide further details of their research if necessary. There were numerous instances when presenters agreed or did not agree which led to a further mutually beneficial discussion.

Around $85 \%$ of respondents thought that peer review was extremely useful for developing their presentation and language skills and further progress with the research. Almost $78 \%$ of students thought that they considerably improved their presentation and language skills, while $72 \%$ of students reported that peer feedback allowed them to rethink the methodology or approaches and develop new ideas in their research projects. Almost $60 \%$ of students mentioned that peer feedback enabled them to come up with new innovative ideas in their research. The remaining $15 \%$ were generally satisfied with the peer review approach in the 
formative peer assessment of presentations, however they either thought that their own skills of providing peer feedback should be improved, or that in some instances, they received the feedback which was either not sufficiently useful in their view or was not entirely clear and they could not understand how they would apply the suggestions from a fellow student. In order to systematise the feedback received from all students, we will consider the feedback in three major areas: presentation skills, language skills, and everything related to their research projects.

While considering presentation skills, all students reported that the peer feedback they received after their presentations allowed them to improve or significantly improve (36\% of respondents) their skills. They reported particular skills they learned or enhanced in both semesters, e.g. voice projection, the ability to communicate clearly and liaise with the audience, how to engage with the audience more effectively and ask rhetorical questions. They specifically stressed that formative peer review allowed them to rethink their approaches and put the audience in the centre of their attention when presenting the results or the progress of their research. Some students mentioned the importance of eye contact and the ability of the speaker to receive immediate feedback by observing the audience. They also reported better confidence and the ability to convince the audience in their presentations and considered these skills as "newly-acquired". They benefitted from "applying and testing various communicative strategies". Almost all respondents confirmed that they developed an effective and logical structure of their presentations, which enabled them to present logically various aspects of their research.

Many students also mentioned that their language skills improved (45\%) and significantly improved (around 41\%). Other students reported that they learned specific language phrases for offering and receiving constructive feedback and effectively engaging in the discussion while agreeing or disagreeing with their peers. Apart from learning some new academic vocabulary, students particularly appreciated the opportunity of engaging in a discussion of their research and actively using lexical items and grammar they learned during the course or before. They specifically mentioned that they felt more comfortable with the use of various linguistic items and agreeing them grammatically in sentences they formulated. Over half of students confirmed that they felt the coherence and cohesion of their messages has improved as well.

Another area, where students reported considerable progress, was their research. $72 \%$ of students reported that these presentations and in-class oral formative feedback allowed them to either introduce some changes in their research, methodology or literature review or reconsider some approaches and in several cases slightly change their research questions. Some respondents also reported that they did not expect so much useful and constructive feedback from 
students conducting their research in different domains. In some instances, peer feedback contributed to the development of innovative ideas either in the design of their research projects, collecting and analysing data, or methodology. Peer review allowed some students to explore some aspects of their research subjects further.

More generic comments addressed the issue of improved collegiality and teamwork in the group and the possibility of asking fellow students for an informal feedback outside classroom. Some respondents also mentioned that regular peer feedback allowed them to develop their self-assessment techniques. Students also appreciated that they would get more feedback on all aspects of their presentations and research as a whole, e.g. "the feedback I received covered many sides of my performance. It was great. I do not think I would be able to receive so much feedback from my lecturer alone”.

In the last round of presentations at the end of the course, students received marking criteria for assessing oral presentations that made the peer review more focused in some specific areas. A few students thought that peer review with the marking criteria is more effective, while some other students considered these criteria somewhat restrictive, especially for innovative developments in research or enhancement of presentation and language skills. Overall, the students were happier with the peer review and found suggestions from other students extremely constructive and memorable. One of the students wrote in the questionnaire, that she remembered better the feedback from students and was able to improve her presentation and language skills, especially one mistake which she used to make all the time before.

The feedback at the end of the modules showed significant improvements in presentation and language skills and led to positive and sometimes innovative changes in their research. Apart from these major themes, students also pointed out such themes as confidence, the development of self-evaluation and selfcontrol techniques, understanding the importance of the audience and the ability of effective engagement with their listeners. Peer review proved to be an effective tool in developing an array of skills and enhancing student performance overall.

\section{Conclusions}

Our findings confirm that formative in-class peer review is not regularly used in assessing presentations presented by students, as well as their participation in discussions, role-plays, mock negotiations, etc. At the same time, some initial results of our research show that formative in-class peer review can be an important tool in effective development of presentation, language and research skills. In view of the current globalisation processes and increased exchange of information through conferences, webinars and other electronic forms of 
communication, it is becoming even more important to allocate more time to practising presentation skills using peer review in our modules. The research confirmed that the UCL's connected curriculum framework allows effective development of those skills and ensures that the curriculum of all modules supports students' research projects and continuous enhancement of their research and related skills.

Our research also demonstrated that apart from developing necessary skills of students, formative in-class peer review contributes to fostering soft skills, e.g. teamwork, the ability to provide and receive constructive feedback. It also creates better cooperation in class and enables all participants in teaching and learning to develop some elements of community of practice and engage more effectively with learning across all disciplines. It is also important that many challenges and fears of direct feedback expressed at the beginning of the course did not materialise. On the contrary, our findings based on one year showed that peer review allowed students to progress better in their research and taught them critical and analytical thinking beyond their discipline which is the principal objective of the connected curriculum framework and cross-disciplinarity.

Our findings also showed that formative in-class peer review does not substitute the formative feedback students receive from their teacher but adds another important perspective and allows students to liaise better with their peers and understand the audience better. As it was established in our research, students realised how crucial the audience is for the success of their presentation. This link between the speaker and the audience allows researchers to get constructive feedback and may enhance their current research or open new exciting areas or important links.

The research also showed the significance of establishing what was particularly good in the presentation, which is often omitted in constructive feedback. It was crucial for students to see good examples of approaches in presentations and research or perhaps better ways of explaining specific issues that could be replicated and used by other students. In a way, this is becoming an effective way of sharing good practice, and the process of formative in-class peer review should fully support it.

It is also vital to mention, that we consider our findings as initial or preliminary since we will compare the data received in 2018/19 academic year with the data in 2019/20. We hope that this comparison will form a better foundation for us to draw conclusions and possibly develop a few other aspects of this research, e.g. to explore self-assessment or other relevant subjects which were mentioned by students in their feedback. 


\section{References}

Bainbridge, J., \& Sandford-Couch, C. (2018). Legal history and student involvement in the assessment process. Journal of International and Comparative Law, 5(1), 259-278.

Higgins, M., Grant, F., \& Thompson, P. (2010). Formative Assessment: Balancing Educational Effectiveness and Resource Efficiency. Journal for Education in the Built Environment, 5(2), 4-24.

Huisman, B., Saab, N., van den Broek, P., \& van Driel, J. (2019). The impact of formative peer feedback on higher education students' academic writing: a Meta-Analysis. Assessment and Evaluation in Higher Education, 44(6), 863-880.

Liu, N.F., \& Carless, D. (2006). Peer feedback: The learning element of peer assessment. Teaching in Higher Education, 11(3), 279-190.

Malyuga, E.N. (2009). The problem of the business negotiations language as genre of intercultural business communication. Russian Journal of Linguistics, 3, 52-60.

Min, H.-T. (2006). The effects of trained peer review on EFL students' revision types and writing quality. Journal of Second Language Writing, 15(2), 118-141.

Mulder, R.A., Pearce, J.M., \& Baik, C. (2014). Peer review in higher education: Student perceptions before and after participation. Active Learning in Higher Education 15(2), 157-171.

Nicol, D. (2014). Guiding Principles for Peer Review: Unlocking Learners' Evaluative Skills. In Kreber et al. (Eds.), Advances and Innovations in University Assessment and Feedback (197-224). Edinburgh: Edinburgh University Press.

Springer, L., Stanne, M., \& Donovan, S. (1999). Effects of Small-Group Learning on Undergraduates in Science, Mathematics, Engineering, and Technology: A MetaAnalysis. Review of Educational Research, 69(1), 21-51.

Topping, K.J. (1998). Peer Assessment between Students in Colleges and Universities. Review of Educational Research, 68(3), 249-276. 